\title{
РУССКАЯ ДИАСПОРА НА КИТАЙСКОЙ ЗЕМЛЕ: ВАРИАНТ КУЛЬТУРНОЙ ГИБРИДНОСТИ ${ }^{1}$
}

\author{
Мещеряков А.Ю., Антропов О.К.
}

Мещеряков Александр Юрьевич, Астраханский государственный университет, 414056, Астрахань, Россия, ул. Татищева, 20а. Эл. почта: daomesheryakov@ gmail.com

Антропов Олег Константинович, Астраханский государственный университет, 414056, Астрахань, Россия, ул. Татищева, 20а. Эл. почта: olegantropov1 @ gmail.com

Авторы анализируют процесс культурной гибридизации в русской диаспоре Китая. Процесс культурной гибридизации - это скрещивание культур или их пересечение, где образуются новые условия, свойства, законы и иные экзистенциональные нормы. Процесс культурной гибридизации в истории видится авторами в самых разнообразных формах. Культурная гибридность возникает в таких местах, где на протяжении долгого времени осуществляются расовые, языковые, религиозные и прочие культурные контакты. Именно в диалоге культур рождается культурная гибридность. Культурный диалог с Другим/Чужим на китайской территории способствовал зарождению культурной гибридности. «Русская диаспора в Китае» - идеальное место для изучения культурной гибридности, так как представляет собой место пересечения русской и китайской культуры.

Особой формой межэтнического взаимодействия русских и китайцев стал смешанный русско-китайский брак, находящийся «Между» двух культур. В результате межрасовых, смешанных, интернациональных браков появлялось поколение детей метисов - носителей новой культуры. Культурная идентичность иммигрантов на чужой территории в любом случае изменялась и превращалась в иную идентичность гибридную идентичность. Процесс культурной гибридизации в конечном итоге привел к появлению целого ряда новых культурных свойств, форм, явлений в истории России и Китая. В статье представлены образы восприятия гибридного пространства, транслируемые в общероссийскую культуру носителями этого опыта культурной гибридности - русскими поэтами, художниками, музыкантами, актерами и мн. др. По мнению авторов, культурная гибридность в различных местах и периодах истории разнообразна и имеет свою уникальную специфику по целому ряду причин.

Ключевые слова: гибрид, культурная гибридность, межкультурная коммуникация, гибридная идентичность, гибридное пространство, Другой/Чужой, русская диаспора, русская иммиграция, Россия, Китай.

Британский историк культуры Питер Бёрк заметил, что в истории культурные встречи и культурный обмен способствуют творчеству людей. В своем труде он также обращает внимание на то, что культурная гибридность особенно заметна в области музыки, где возникают гибридные формы и жанры (2009 стр. 1-6). В 2005 г. американец

\footnotetext{
1 Статья выполнена при поддержке РФФИ 17-33-01069 «Встреча с Чужим: российский и
} дальневосточный опыт межкультурной коммуникации» 
азиатского происхождения Кристофер Тин создал песню «Baba Yetu». Данная песня первоначально была названа «Отче наш», а затем переведена на язык межэтнического общения в Африке - суахили. Она была исполнена американцем совместно с группой Стэндфордского университета. Затем для издания в дебютном альбоме была перезаписана с южноафриканской группой Soweto Gospel Choir. В результате песня «Baba Yetu» получила множество наград и была представлена на различных площадках и мероприятиях по всему миру, включая «Дубайский фонтан», «Кеннеди-центр», «Королевский фестивальный зал», «Голливудскийбоул» и новогодний концерт на 67-ой сессии Генеральной Ассамблеи ООН. Это уникальное произведение можно смело назвать не только песней народов или песней мира, символизирующей дружбу различных этносов, но и «культурной гибридностью». В данной песни нет четкой культурной границы - она размыта, в ней отсутствует точный культурный континуум. Подобную гибридность можно наблюдать в музыкальном клипе «Baba Yetu» в исполнении Alex Boye и группы «BYU Vocal Point» университета Бригама Янга.

В 1976 г. английский эволюционный биолог Ричард Докинз написал популярную работу «Эгоистичный ген», где указал, что философия и предметы, известные под названием «гуманитарные», по-прежнему преподаются так, как если бы Дарвина никогда не было на свете (1976 стр. 12). Британский исследователь постколониальной теории Роберт Янг в своей книге (1995) уделяет дарвинизму особое место, тем самым открывая перед нами возможность к исследованию культурной гибридности. «Конечно, Дарвин не имел возможности сказать ничего решающего о гибридности. Нэнси Стефан замечает, что без понимания генетики гибридность в эволюции была бы слишком сложной проблемой для Дарвина» (стр. 11-12). Но, важно понимать, что именно Дарвин подводит нас к первоначальному пониманию процесса культурной гибридизации в данном исследовании.

Разумная жизнь на нашей планете достигает зрелости, когда ее носители впервые постигают смысл собственного существования. Человек - это не просто высшая ступень в эволюции, это эволюция, осознавшая саму себя. Большую часть всего, что есть необычного в человеке, можно вместить в одно слово - «культура». Новый бульон - это бульон человеческой культуры (Dawkins, 1976, стр. 156-158). Если представить этнические группы людей в качестве видов или разновидностей, то существенной разницы в рамках биологии между ними нет, но есть несоизмеримые отличия и множественное разнообразие в их культурах. Если мы посмотрим на человека под другим углом, где в качестве вида или разновидности будет выступать раса, то следует обратиться к словам 
Генри Хотзе, который утверждает, что различия в расах будут существовать пока существуют расы (Young, 1995, стр. 13).

В свою очередь, Роберт Янг в рамках гибридности формирует понимание о человеке и культуре. «Гибрид (Hybrid) - это слово XIX века. Но мы вспоминаем его снова. В XIX веке данное слово использовалось для обозначения физиологического явления. В XX веке слово «гибрид» было оживлено для описания культуры, в то время, когда культурные факторы определяли физиологическое состояние» (стр. 5). Учение о постоянстве типа могло бы обойти проблему видов, но ей пришлось столкнуться с процессом гибридизации. Об этом хорошо свидетельствует неограниченная рождаемость детей в межрасовых браках. История опровергает мнение о невозможности плодородности человеческих гибридов (стр. 12-13). Помимо академического интереса, эта тема безусловно важна для самого человека. В современно мире она затрагивает практически все аспекты его жизни.

Вероятнее всего «культурная гибридность» (Cultural Hybridity) больше является процессом, нежели результатом. Это процесс, в котором происходит скрещивание культур или их пересечение, образуются новые условия, свойства, законы и иные экзистенциональные нормы. Процесс культурной гибридизации в истории и современности видится нами в самых разнообразных формах.

Роберт Янг анализирует культурную гибридность на историческом фоне. «Обе модели культурного взаимодействия, языка и пола, сливаются в единый продукт, который характеризуется термином - гибридность». Он предполагает, что человеческая раса является гибридной, и что понятие гибридность может служить в качестве «универсального описания культуры» (1995, стр. 5).

Российский историк Якушенков С.Н. замечает, что культурная гибридность возникает в таких местах, где на протяжении долгого времени осуществляются расовые, языковые, религиозные и прочие культурные контакты (2016, стр. 419-422). Новая гибридная культура отличается особым своеобразием и синкретизмом. Соседство с местными народами приводит к активному заимствованию множества культурных элементов (2016, стр. 5-21).

Вполне закономерно, что не каждая культура является гибридной. Питер Бёрк в своей работе обращает внимание: «Если каждая культура является гибридной, то данная концепция теряет свою ценность». Питер Бёрк анализирует культурную гибридность как явление в контексте культурного обмена: «В истории процесс культурной гибридизации в определенных периодах и пространствах проходил где-то сильнее или быстрее, а где-то медленнее». По мнению Питера Бёрка, культурной гибридностью можно назвать новые культурные пространства, явления, 
факторы, свойства, которые возникли в следствии культурного столкновения двух или более культур (2012, стр. 13-14). Питер Бёрк упоминает, что всякая инновация в культуре является адаптацией этноса, следовательно, культурные столкновения способствуют творчеству. Культурный обмен - это не просто культурное обогащение (2009, стр. 6).

Три эти идеи представленных исследователей приводят нас к выводу о том, что именно в диалоге культур рождается культурная гибридность. Процесс культурной гибридизации не подчиняется спланированному плану действий, так как исторический процесс не осуществляется по заранее написанному кем-то сценарием. Также не стоит забывать, что культурная гибридность возникала в разных местах на протяжении большей истории человечества на нашей планете.

Исходя из вышеупомянутых идей начальной точкой процесса культурной гибридизации является встреча различных культур. Особое место в процессе культурной гибридизации занимает союз мужчины и женщины разных культур. Так как процесс зарождения человека (будущего метиса) начинается с оплодотворенной клетки - единичной клетки, которая находиться «Между» («in-between») различных культур отца и матери. Ричард Докинз называет подобную единичную клетку «узкое горлышко», которое в эмбриональном развитии расширяется, превращаясь в множество клеток - невероятное разнообразии, которое в дальнейшем становится человеком. Эта стадия служит своего рода точкой отсчета (Dawkins, 1976, стр. 206). Никто не мог подумать изначально, что первые контакты русских женщин и китайских мужчин приведут к формированию удивительного разнообразия культуры - «гибридной культуры» в русской диаспоре Китая. Встреча с Другим/Чужим неким образом подготовила основу для начала процесса культурной гибридизации. Поэтому процесс культурной гибридизации нужно рассматривать через призму «встречи с Другим/Чужим» (Cultural Encounters). Именно Чужие на Чужой земле способствовали зарождению единичной клетки - «узкого горлышка». В истории Другой/Чужой - это инаковость, способная порождать процесс культурной гибридизации. Чужой экстраординарен, т.е. не соответствует привычному взгляду на человека. Он выглядит по-особому, говорит на незнакомом языке, его одежда, привычки и обычаи - все вызывает недоумение и настороженность. Это инаковость, т.е. вынесение за пределы норм. В следствии межкультурной коммуникации начинается активный процесс ксероморфизма - процесс формирования тела Чужого как страшного, опасного, угрожающему собственному миру или как неприятного, недостойного, отталкивающего. Данный процесс основывается на алиментарных, вестиментарных и сексуальных традициях этноса (Якушенков, Романова, Якушенкова, 2011, стр. 189-195). Плюс 
смешивание культур происходит не только из-за пересечения алиментарных или вестиментарных традиций, языка или хозяйственного уклада. Смешивание происходит на уровне ментальности, формирования новой картины мира, в которой Свой и Чужой встраиваются совершенно новым способом (Якушенков, Якушенкова, 2016, стр. 5-21). Поэтому чтобы понять и оценить важность процесса культурной гибридизации в истории необходимо исследовать множество культурных факторов, возникших вследствие межкультурной коммуникации. В данной статье мы остановимся не только на алиментарных, вестиментарных, и сексуальных предпочтениях этноса.

На сегодняшний день ученые с трудом могут точно ответить на вопрос, где начинается процесс культурной гибридизации, и где он заканчивается? Заканчивается ли он вообще? Следует ли считать гибридное пространство результатом или же это продолжения большого процесса гибридизации? С чем больше связана культурная гибридность с источником ее появления или же с разнообразием гибридных культур? Подчиняется ли процесс культурной гибридизации строгому плану, где образование новых культур происходит постепенно или же это скачкообразное изменение свойств культуры? Наша главная задача в исследованиях ответить на эти интересные вопросы. К сожалению, наука не всегда оперирует точным инструментарием. Поэтому говоря о процессе культурной гибридизации, гибридной культуре, гибридной идентичности и гибридном пространстве необходимо анализировать данные феномены сразу в нескольких плоскостях и в нескольких научных направлениях.

В своей статье мы попытаемся проследить процесс формирования культурной гибридности на примере русской диаспоры в городах Китая (конец XIX - начало XX вв.) в контексте истории и межкультурной коммуникации китайцев и русских. Процесс культурной гибридизации помогает нам лучше понимать культурные изменения в истории русской диаспоры в Китае, а также в других местах нашей планеты. Мы постараемся показать, что «культурная гибридность» больше чем процесс, нежели результат. «Русская диаспора в Китае» - идеальное место для изучения культурной гибридности, так как представляет собой место пересечения русской и китайской культуры, является местом особых исторических обстоятельств в отдельных городах Китая. «Русская диаспора» во всеобщем смысловом понимании - это различные виды концентрации русского этноса в городском ландшафте различных регионов мира.

Р. Янг замечает, что процесс культурной «диаспоризации» означает преднамеренную культурную гибридизацию, процесс объединения, а также диалогизацию этносов и культурных различий (1995, стр. 23). Таким образом, можно уверенно сказать, что гибридность - результат 
проживания Другого/Чужого этноса на чужой территории, непознанном мире, неизвестной земле, пространстве чужеродной цивилизации. Общество, находящееся в новых географических пространствах, вынуждено формировать новую картину мира, которая в полной мере отвечала бы новым условиям. Эта картина мира находит свое отражение в языке, религии, литературе, фольклоре, искусстве, идеологии, поведенческих стереотипах и т.д. Конкретный набор этих факторов создает национальную картину мира, выполняющую важную функцию адаптации к различным условиям, как природным, так и социальным (Якушенков, Якушенкова, 2016, стр. 5-21).

Мы будем прибегать к использованию методологических наработок российской, китайской и американской науки: использование постколониальной теории для анализа процессов культурной коммуникации; применение методов городской антропологии; изучение образа Чужого/Другого (Cultural Encounter) - одного из уникальных методов познания исторического процесса; использование понятий процесса культурной гибридизации, культурной гибридности, гибридной идентичности, гибридного пространства, которые помогут понять генезис межкультурной коммуникации в рамках пространства русской диаспоры, ее исторического развития и формирования идентичности населения. При анализе межкультурного диалога китайцев и русских нами учтены история, культура и периодизация русской диаспоры в Китае.

Русская иммиграция в Китай. Точки соприкосновения русской и китайской культуры формировались в истории России и Китая намного раньше времени образования русской диаспоры в Китае. Самыми ранними русскими иммигрантами в Китае были русские старообрядцы, которые бежали от религиозных преследований при императрице Екатерине II более 200 лет назад. Они селились на северо-западе Алтайского края образуя деревни, где сохраняли свою веру (Shear, 2013, стр. 292-298). Следует обратить внимание на то, что присутствие русских в Китае как диаспоры насчитывает не более 200 лет.

Значительная русская иммиграция начинается в 1897 г. в результате строительства Китайско-Восточной железной дороги, проходящей через всю северо-восточную часть территории Китая. А в 1903 г. эта железная дорога была построена, что позволило русским активнее мигрировать по всей территории, где была проложена железная дорога (Го, 2012, стр. 71 77).

На протяжении долгого исторического процесса русские женщины иммигрировали в Китай в силу различных причин: война, революция, экономические трудности, высокая смертность мужчин, половая диспропорция в России, пьянство мужчин, рождение детей вне брака, супружеские измены и др. В Китае можно было встретить много русских 
женщин (Тарасов, 2016, стр. 102-121). Женщины по одиночке или группами, например, по несколько сестер перебиралась на китайский берег Аргуни в поисках лучшей жизни. Половые диспропорции в российском обществе компенсировались за счет обратной диспропорции в китайском, которое выступало в роли принимающего (стр. 102-121).

Окончание Гражданской войны в России в октябре 1922 г. привело к тому, что с Дальнего Востока в Китай и другие страны иммигрировало около 1 млн. человек. Первым пунктом назначения иммиграции являлся город Харбин, где у русских была возможность обеспечить себе существование. Русские девушки стремились уехать из Харбина, чтобы искать себе женихов в других городах Китая (Хисамутдинов, 2013, стр. 124-127). В китайской литературе о России отмечается высокий процент разводов в России: «если будите гадать русским по руке - смело говорите, что он (она) будет женат два раза; если вдруг ошибетесь, значит, браков будет не два, а три». Причиной разводов китайские исследователи называют: «Несмотря на то, что русские стремятся к сексуальной свободе в сексуальных отношениях, большинству населения не хватает соответствующих знаний в этой области, что приводит к отсутствию гармонии в браке» (Тен, 2010, стр. 189-200).

В данном исследовании особой формой межэтнического взаимодействия русских и китайцев нами был выбран смешанный русскокитайский брак, находящийся «Между» двух культур. Брак в таких условиях - это способ коммуникации. В основном это брак между: мужчиной-китайцем и женщиной-русской. Русские мужчины на китаянках женились очень редко (Оглезнева, 2010, стр. 6-25). Для русских мужчин китайские женщины были чаще всего не более чем объект, который можно использовать для удовлетворения сексуального желания. Брак русского и китаянки не встречал одобрения в России. Поэтому сексуальное насилие становилось обычным явлением, хотя оно не поощрялось.

Русские женщины и китайские мужчины активно способствовали формированию процесса культурной гибридизации. Многие русские женщины, вышедшие замуж за китайцев, придерживались своей веры, крестили своих детей, а иногда и сами китайцы принимали православие (Монгуш, 2016, стр. 2-8). Часто православие сливалось с китайскими верованиями (Ставров, 2016, стр. 116-133).

Помимо китайцев русские женщины вступали в брак с маньчжурами. Маньчжуры учитывали, что, имея помощницу в лице русской женщины, они будут иметь хорошую хозяйку. Многие русские женщины в Китае устраивали жизнь успешнее, становясь женами иностранцев (Хисамутдинов, 2013, стр. 124-127).

Как мы уже упомянули ранее, особое место в процессе культурной гибридизации является союз, брак, межрасовая связь, сексуальные 
отношения русской женщины и китайского мужчины. Плюс ко всему, при первых контактах с Другим/Чужим, и особенно при самой первой встрече, мы очень озабочены сексуальностью Чужого (Якушенкова, 2014, стр. 346352). Сексуальная культура, сексуальность или секс Другого/Чужого актуальны в данном случае.

Сексуальные традиции русских приковывали пристальное внимание китайцев. Многие традиции рассматривались в негативном ключе. Отношения между мужчиной и женщиной в царской России не описаны как целомудренные и «консервативные» в отличии от восточных обществ. Среди некоторой части китайского населения существует не только стереотип о «моральной распущенности», присущей жителям России, но даже о «культе секса» в российском обществе (Тен, 2010, стр. 189-200). Другая/Чужая женщина рассматривается как объект мужского желания, она сексуально распущенная, гиперсексуальная. Как правило, Другой/Чужой - сексуальный насильник или человек, помешанный на сексе. Насилие к Другой/Чужой женщине доминирующая норма (Якушенкова, 2014, стр. 346-352).

В соответствии с современными представлениями китайцев, молодые русские женщины необычайно красивые: «золотистые волосы, зеленые глаза», стройная фигура, длинные ноги. Китайские авторы отмечают, что женщины в России умеют со вкусом одеваться. Они подчеркивают особое умение русских женщин элегантно носить юбки. Китайские женщины «сначала задирают юбку, а потом садиться, чтобы ее не помять», а женщины в России «аккуратно прижимают юбку к телу, а потом садятся» (Тен, 2010, стр. 189-200).

Русские женщины иммигрировали в Китай не только вдоль береговой линии, но и во многие китайские города. Русские девушки работали в ресторанах, барах, танцевальных залах, гостиницах, на показах моды и кабаре. Часто русские девушки, приезжавшие из Харбина в Шанхай в надежде найти себе жениха и работу попадали в публичные дома. Бизнес процветал везде, где работали русские девушки, так как китайцы покровительствовали этим заведениям, находили их экзотическими. Белая женщина была воплощением западного образа жизни и современности на протяжении всего XX века в Китае. А китайские женщины являлись признаком феодального гнета для многих китайских мужчин. Хорошим примером является сериал «Русские девушки в Харбине» (1994), где центральное значение занимают китайские мужчины, позиционирующиеся как владельцы власти и капитала, а иностранные женщины, желающие заработать являются подчиненными экономическому господству китайских мужчин. Другим примечательным примером является фильм «Дикий поцелуй» (1995), в котором возможность подчинить иностранных женщин себе символизирует не 
только возрождение маскулинности китайцев, но и подъем самой китайской нации (Sheldon, 2000, стр. 25-47).

Сексуальная идентичность Другого/Чужого актуальна в изучении не только на первоначальной стадии, но и на протяжении всего процесса культурной гибридизации, так как наилучшим образом отображает встречу и смешивание двух или более культур.

От гибридной идентичности к гибридной культуре. Всеобщими терминами обозначающими русских в Китае считаются элосыцзу жэнь (俄 罗斯族人) и элосы жэнь. Также можно встретить термин «русские в Китае» (чжунго дэ элосыцзу). В массовом сознании китайцев второй термин служит для обозначения как гражданской, так и этнической принадлежности. Во многих русско-китайских словарях между этими понятиями нет четкого различия (Тен, 2010, стр. 189-200). Термины элосыцзу жэнь и элосы жэнь несут историческую значимость в изучении гибридной идентичности русских в Китае. Современные элосыцзу - это потомки браков между русскими и китайцами, что позволяет отнести данный термин к гибридности. В обиходе и иногда в научной литературе используют термин хуньсюжень (混血人) - люди со смешенной кровью, т.е. метисы. В повседневности иногда употребляется слово эрмаоцзы (二毛 子) - обрусевшие русские, потомки межнациональных браков, данное слово несет негативный оттенок. В настоящее время китайцы используют термин элосыцзу, либо хуаэ хоуи (华俄后裔) - потомки китайцев и русских (Ставров, 2016, стр. 116-133). Также можно встретить термин «русский харбинец», который появился вместе с основанным 16 мая 1898 г. городом Харбином. Прибывшие на место строительства главного узлового центра КВЖД русские работники стали не только основателями молодого города, но и первыми его жителями на китайской земле (Курто, 2011, стр. 131145).

«Русская народность Китая» имеет небольшую численность, но при этом входят в число 56 национальностей, проживающих в настоящее время на территории Китая. Они также представляют одно из 22-х национальных меньшинств в Китае численностью менее 100 тысяч человек (Тарасов, 2016, стр. 102-121). Заметим, что в Китае существует особое направление национальной политики - охрана культуры этнических меньшинств. Законодательство Китая защищает право неханьских народов на сохранение и развитие традиционной культуры, религии, верования и языка (Ставров, 2016, стр. 116-133). 
В результате межрасовых, смешанных, интернациональных браков появлялось поколение детей - метисов. Данный момент в истории Китая и России, показывает, что культурная идентичность иммигрантов на чужой территории в любом случае изменяется и превращается в иную идентичность, совершенно незнакомую человечеству - гибридную идентичность. Следовательно, русская диаспора в Китае - это смешанное пространство, где проживают не только русские и китайцы.

Создаваемая совершенно новая культурная ситуация порождает особые гибридные личности, совмещающие в себе множество культур (Якушенков, Якушенкова, 2016, стр. 5-21). Между культурами нет четкой или устойчивой культурной границы или культурного континуума. Разнообразное смешивание и культурное взаимодействие, происходящее в Китае между русскими и китайцами привела к поиску новой идентичности - гибридной идентичности.

«Каждый день с самого рождения мои пути пересекались с китайцами, - вспоминает Ксения Волкова, родившаяся в Китае и прожившая в нем до 1954 года. - Мы русские всегда жили рядом с ними. Китайцы нуждались в нас также, как и мы в них. С детства я привыкала к ним и считала, раз я живу в Китае, значит он такой же мой, как и для китайца его страна. Я ела китайскую еду, играла с китайскими девочками, не чувствуя разницы, кто я и кто моя черноглазая подружка... Родители поддерживали хорошие взаимоотношения с соседями-китайцами, и мы были частью этой страны с ее укладом и бытом» (Старосельская, 2006, стр. 32).

Сложилась внутренняя разница между русскими-китайцами. Жители современного китайского приграничья являются уже редко вторым, чаще третьим, а в основном четвертым и пятым поколением потомков межнациональных браков начала XX века. Родоначальниками современных «русских» фамилий будут русская прабабушка и китайский прадедушка, рожденные в начале XX века. В 1954 г., когда часть китайскороссийских потомков вступали в китайское гражданство, большинство выбирало себе нацию «хань», которая является основным этническим образованием Китая, а не русскую нацию, которая составляла в Китае этническое меньшинство, по причине нежелания возвращаться в Советский Союз (Мяо, 2015, стр. 128-135). В Харбине русских, менявших гражданство, называли «харбинские редиски» - красные снаружи, белые внутри (Barker, Gheith, 2004, стр. 154).

В 1990 г. многие изменили свою национальность с ханьцы на русские, когда в Китае провозгласили равноправие национальных меньшинств (Го, 2012, стр. 71-77). Одни метисы склонялись к принадлежности китайского народа, другие к русскому. Некоторые могут называть себя «настоящими китайцами», некоторые из них в пользу 
наличия гибридной идентичности могут идентифицировать себя как российско-китайских или китайско-российских личностей, русскими азиатского происхождения или китайцами русского происхождения, синьцзянскими русскими и мн. др. Новая идентичность, отличается от прежней, начальной, она не зависит от России или Китая, она зависит от культуры, которая сформировалась в результате межкультурного диалога китайцев и русских.

Само понятие самоидентификация означает попытки определить свое место в мире, доказать самим себе свое исключительное право на существование. Французский философ П. Рикёр в своей книге «Самость и инаковость», самость (self), т.е. наша сущность (идентичность - same, identity), «обнаруживает себя в контексте сравнения; еe противоположностями являются Другой, противоположный, различный, непохожий, неравный, обратный». Но наша самость есть еще и наше право быть другим (Романова, Хлыщева, Якушенков, Топчиев, 2013, стр. 37).

Некоторые российские исследователи в своих работах поднимают вопросы национальной, культурной, этнической идентичности или сохранения этничности, самобытности. Они утверждают, что в некоторых русских диаспорах Китая произошел процесс «окитаивания», «китаизации» в результате чего сформировался «окитаенный» русский. Другие наоборот считают, что в русских диаспорах существовали эффективные способы сохранения и развития русской идентичности, не позволяющие «китаизировать» русских или стать «китаянами» китайскими русскими. Оба мнения уводят нас в заблуждение - они ошибочны, так как в результате межкультурной коммуникации русских и китайцев появлялись дети-метисы, не принадлежащие ни к русской, ни к китайской культуре. Русские в Китае являются метисами, некоторые из них более гибридны, чем другие. Первое и дальнейшие поколения метисов будут принадлежать к «промежуточному» пространству, которое находиться «Между» двух культур: русской и китайской, а то и больше. Всему этому название «гибридная культура», где преобладает различное сочетание форм, свойств различных культур, где границы идентичности пересекаются (X). Происходит не доминирование какой-то одной культуры, а смешивание различных культур, где возникает сложная проблема выбора, принадлежности к культуре, этносу, нации, стране и др. - формируется состояние культурной гибридности. Эта удивительная гибридность российских иммигрантов, является результатом встречи с Другим/Чужим и пересечением с его культурой, рождением единичной клетки - будущего метиса. Все это следует определять, как универсальное явление в истории человечества.

Процесс культурной гибридизации продолжается в результате появления первого поколения метисов, которые в свою очередь 
продолжают создавать «промежуточное» пространство. Метис - это наиважнейший субъект процесса культурной гибридизации. Культурная гибридность «промежуточного» пространства особенно ярко отражается в городском ландшафте и произведениях самих гибридов.

Формирование русской диаспоры. Тенденция к расселению этнической диаспорой преобладала в течении долгого времени активной иммиграции русских в Китай. Русская диаспора в Китае начала формироваться в XVII в. (Курто, 2011, стр. 131-145). В начале XX века, с открытием КВЖД, в Китае стали бурно развиваться группа городов. Особое значение приобрел город Харбин - центр провинции Хэйлунцзян (известный как «Восточный Париж», «Восточный Петербург», «Восточная Москва»), который быстро превратился в международный центр (Тен, 2010, стр. 189-200).

Российский ученый Старосельская Н.Д. в своей книге (2006, стр. 42) отмечает: «Пестрый, шумный, яркий, многонациональный, этот город действительно в чем-то схож с Санкт-Петербургом, а местами - с Москвой и другими крупными городами Российской империи. Возникнув на месте маленького китайского селения, он как-то очень быстро вырос и приобрел важное значение для всей Маньчжурии».

Со временем Харбин стал чудом современной китайской урбанизации. Харбин стал центром моды в одежде, еде, кино, театра, музыки и мн. др. Русская иммиграция не была единственной. В Харбине присутствовали другие представители европейской культуры - французы, итальянцы, англичане, немцы, поляки и мн. др., которые так же оказывали свое влияние на культурный облик города - образуя харбинскую архитектуру, алиментарную и вестиментарную культуры с международным колоритом (Мяо, 2015, стр. 128-135). «Что же это за штука - Харбин: Европа или Азия?» или «Это Россия или Китай?» жители этого города стали задавать себе эти вопрос с начала 1920-х гг. «Мы оказались среди двух миров, - писала русский поэт Л.Ю. Хаиндрова - Харбин был китайским городом. Харбин оставался старорежимным русским городом, и о нем можно было сказать здесь русский дух, здесь Русью пахнет» (Хаиндрова, 2003, стр. 274). Харбин является «перекрестком» культур, инаковым местом или пространством «Между», где в основном смешивается две культуры: Россия и Китай. Харбин - это гибридное город.

Исследователи творчества поэтов и писателей русского Харбина отмечают, что их произведения вобрали в себя традиции классики и «серебряного века», «монпарнасские» веяния и экзистенциональные мотивы (Аурилене, 2013, стр. 128-136).

Города Харбин, Порт-Артур и Дальний (Далянь) сочетали в себе гибридную планировку, смешивающую в себе две относительно 
самостоятельные части - китайскую и европейскую. Большинство европейских тенденций были инкорпорированы из Москвы и СанктПетербурга. В основу проектов новых городов, возникавших на заре нового века, была заложена идея города-сада. Город-сад - это иная концепция, которая берет свое начало от англичанина Э. Говарда. Особую популярность идеи Э. Говарда получили среди руководства железных дорог. В этих городах проявился передовой характер самой отрасли, ее ориентированность в будущее, связь с европейской системой образования, да и в целом высокий уровень образованности (Якушенков, 2017, стр. 1517). Город-сад предполагал единовременное создание живописной планировки всего участка состоящей из домов на одну семью и необходимой инфраструктуры - культурных, образовательных, спортивных, развлекательных учреждений, а также района с производственными предприятиями (Корчагина, 2016, стр. 668-675).

Одним из смешанных мест города Харбина являлся Зеленый Базар с узкими извилистыми улочками, плотно застроенными различными домами. Зеленый Базар являлся рынком для горожан, а также находился между Новым Городом и Корпусным, Госпитальным городками. В сложных условиях перенаселенности района в нем существовала харбинская бедность. Иммигранты добавляли Зеленому Базару культурной гибридности. Самая бедная часть иммигрантов оседала именно в этом районе, пытаясь построить собственный дом. Там жили русские и китайцы, смешивались языки, привычки, быт. Каждый район Харбина застраивался быстро и хаотично, и уже с 1914 года «Зеленый Базар» не выделялся своей экзотичностью на фоне других районов Харбина.

А в любимом месте отдыха харбинцев - районе Затон, можно было встретить русских и китайских лодочников на традиционных китайских лодках с именами «Москва», «Наташа», «Рязань», «Казань», «Красотка». (Старосельская, 2006, стр. 59-61).

В фильме японского режиссера Симадзу Ясудзиро «Watashi no uguisu» (1994), город Харбин представлен современным западным городом в Китае с особой природой, имеющим православные соборы, большие кресты и музыку.

К началу 1940-х в Харбине было более 20 православных храмов и более десятка культовых построек других конфессий. Сегодня в городе действует одна православная церковь, хотя сохранилось их пять. Сохранились костел, синагога, мечеть, однако они не используются по своему прямому назначению (Крадин, 2001, стр. 83).

Во второй половине XIX века начала формироваться полиэтническая - преимущественно русская диаспора - Трехречье Саньхэ цюй (Внутренняя Монголия). В данном регионе русская диаспора представляли из себя деревни (Забияко, Забияко, Зиненко, Чжан Жуян, 
2016, стр. 109-125). Например, русская национальная волость Эньхэ в Барге. Жизнь русских в Трехречье является результатом длительной истории формирования русской диаспоры на этой территории. В 70-е годы XIX на правобережье Аргуни на китайской территории постоянно возникали золотые прииски, туда проникали русские для добычи золота. В то же время после отмены запрета на заселение ханьцами северовосточных провинций Китая китайские переселенцы стали масштабно осваивать эти территории. Часть из них нанимались на золотодобывающие прииски к российским капиталистам. Междуречье притоков Аргуни Гана, Хаула и Дербула - стало активно заселяться русскими после 1920 года (Тарасов, 2016, стр. 102-121).

Помимо Харбина и Трехречья русская диаспора формировалась в отдаленной провинции Северо-Западного Китая - Синьцзян (также называемый китайский Туркестан). Русский след в данном регионе довольно глубокий. Активные русские диаспоры провинции Синьцзян сформировались в Кашгаре, Чугучаке, Кульдже, Хотане и Урумчи. В урбанистическом ландшафте этих городов подробно прослеживается русское культурное наследие. Это ставни и различные наличники на окнах домов, старые потемневшие русские вывески, скамейки у массивных ворот. В центре Кульджи сохранилось несколько зданий бывшего российского консульства, а также сохранился «русский квартал» (Монгуш, 2016, стр. 2-8). Русские диаспоры Синьцзяна включали в себя не только этнических русских, но и евреев, узбеков, киргизов, казахов и мн. др. народы, которые мигрировали в Синьцзян по разным причинам. Религиозно русская диаспора Синьцзяна также очень разнообразна православные русские, иудеи, старообрядцы, католики, баптисты и мусульмане (Shear, 2013, стр. 292-298). Русские оставшиеся в Синьцзяне в течении долгого времени жили в изоляции от европейской культуры, им приходилось выстраивать особый межкультурный диалог помимо ханьского народа с местными народами неханьского происхождения уйгурами, дунганами, казахами, киргизами, монголами и другими более мелкими этническими группами (солоны, галча, сибо, дулане, чахары, лобыки) (Монгуш, 2016, стр. 2-8).

Со временем сформировались основные центры русской диаспоры в китайских городах: Харбин, Шанхай, Урумчи (Синьцзян), Тяньцзин. Русские школы, театры, клубы, кинотеатры, рестораны, православные церкви, больницы оказывали влияние на этнокультурный облик китайских городов - многое имело этнокультурную специфику. Русский клуб в Урумчи был центром общественной и культурной жизни русской диаспоры, там проводили лекции, танцевали, также имелся театр, концертный зал, балет, ресторан и кинотеатр. Русская диаспора состояла, как из белых русских, так и красных русских (большевики), которые 
заполнили важную нишу в культурной, социальной, политической и экономической жизни Синьцзяна.

В случае с Синьцзяном русская диаспора представляла своим жителя и новоприбывшим русским иммигрантам «зону комфорта» безопасную, культурную, языковую и религиозную поддержку. Русская диаспора имела различные храмы, кулинарные традиции из России, большое количество многообразной русской прессы, разные языки, городские сады и парки, оранжереи, почтовые отделения, банки, библиотеки, консульства, казармы для войск (Shear, 2013, стр. 292-298). Схожую ситуацию мы можем наблюдать и в русской диаспоре Харбина (Курто, 2011, стр. 131-145). Вместе с тем, американский исследователь Майкл Шер замечает, что в Синьцзяне, несмотря на смешанные браки, интеграция между диаспорами была незначительна. Таким образом, отношения между русскими и другими этносами в Синьцзяне были в значительной степени ограничены в общественной сфере (Shear, 2013, стр. 292-298). Это замедлило процесс формирования культурной гибридности.

Культурная гибридность. Алиментарная культура является базовой частью любой этнической и национальной культуры, представляет собой систему культурных кодов, вокруг которых выстраиваются и остальные части культуры. С помощью различных пищевых символов и метафор мы познаем мир, так сказать, «впитывая его с молоком матери». Алиментарная культура встроена в картину мира всех народов с помощью множества механизмов (Якушенков, Сун Цзе, 2015, стр. 247-253). Исходя из этого, алиментарная культура детально отражает сформировавшуюся гибридную культуру в русской диаспоре Китая. В частушках находит отражение непривычность китайской кухни для русских женщин:

\author{
Ой, милочка моя, \\ Почему ты похудела? \\ - За китайцем я была, \\ С пару манты ела \\ (Забияко, Забияко, др., 2016, стр. 109-125).
}

Выбранная нами частушка не относится к гибридной культуре, однако, она косвенно имеет к ней отношение, так как гибридная культура формируется в результате встречи с Другим/Чужим.

Многие блюда были завезены русскими иммигрантами. В Китае русские использовали русские печи для приготовления пищи (Тарасов, 2016, стр. 102-121). Различия кулинарной культуры Китая и России состоят не только в традиции питания, но и в способе приготовления. 
Заметим, что такие семантические поля как «печь 烤》 и «парить 蒸》 имеют как сходства, так и различия (Лю, 2016, стр. 116-121). Изменение кулинарной лексики отчетливо отражает не только межкультурную коммуникацию различных народов, но и процесс культурной гибридизации. Поэтому в условиях активного межкультурного диалога способыприготовления пищи будут зависеть от двух или более различных культур. Вероятно, в культуре появлялось совершенно новое гибридное семантическое поле, которое скрещивает в себе два глагола - русского «печь» и китайского «парить».

Хотелось бы заметить, что русский и китайский языки являются гибридными языками, так как контакты между данными языками в истории очень многочисленны. В истории России и Китая не трудно найти примеры лингвистической гибридизации. После событий Октябрьской революции в России множество слов было заимствовано Китаем. На сегодняшний день в китайском языке используются такие исторические слова как большевик (布尔什维克), меньшевик (孟什维克), советы (苏维埃 ), самовар (茶炊) и мн. др. Лингвистическая гибридизация проявляется также в повседневности китайцев Харбина, которые могут говорить порусски. Многие слова вошли в жизнь не только города, но и китайского языка в отдельных местах Китая, где проживали и продолжают жить русские: мадам, базар, платье, грубая колбаса, блин, пасха, окрошка, пиво и мн. др. Заметим, что наименования таких блюд, как пельмени, манты, плов, шашлык инкорпорировались в русский язык из восточных языков. В прозе русских писателей Харбина содержится два-три китайских заимствованных слова, чаще всего фанза - дом, а также слово чифан-есть (吃饭 - «кит. «обедать, ужинать») (Гончаренко, 2009, стр. 44).

Интересная культурная гибридизация произошла в Харбине с пивом. Пиво импортировалось в 1900 году для того, чтобы удовлетворить потребности русских иммигрантов в Китае. Известный русский предприниматель Улубулевский открыл в Харбине первый пивоваренный завод. Впоследствии под влиянием алиментарной культуры русских иммигрантов харбинцы, которые вначале не понимали вкуса этого напитка, полюбили вкус пива. Неожиданно новая культурная тенденция «пить пиво» приглянулась в Харбине за пределами русской диаспоры. Так пиво превратилось в популярный напиток в Харбине. Каждым летом в Харбине на Центральном проспекте можно наблюдать уникальной культурное явление - пивной фестиваль, где можно увидеть китайцев, русских и иностранных туристов с кружкой пива в руке (Мяо, 2015, стр. 128-135). Так харбинское пиво - xa nu (哈尔滨啤酒) превратилось в самое 
популярное пиво в Китае и стало частью китайской кухни. На сегодняшний день «харбинское пиво» - это огромная корпорация с 14 заводами в разных городах Китая. Крайне редко в ресторанах Харбина можно увидеть столик, на котором не стояла бы бутылка «харбинского» или бокал разливного пива. Многие блюда к пиву, появились в Китае при содействии российской гастрономии. В качестве примера, можно привести закуску к пиву - «вареные раки», «копченая корюшка», «селедка под шубой» (Грибин, 2008).

Здесь уместно вспомнить, что с одной стороны, в России, как и в Китае, для гостей всегда открывают новую бутылку спиртного. Если приглашают друзей в гости, то мероприятие обходится почти в ползарплаты, потому что «дружба дороже денег». Также китайцы обращают внимание: «пьют из больших рюмок, и не маленькими глоточками, а сразу опрокидывая их» (Тен, 2010, стр. 189-200).

Среди товаров, продающихся в «русских лавках» много шоколада, рыбных консервов, паштета из гусиной печени, водки, хлеба, икры. При этом следует отметить, что практически все эти товары произведены в Китае.

В Харбине помимо китайских, можно встретить много ресторанов русской кухни: «Брежнев», «Татос», «12 стульев», «Восточная Москва», «Гоголь бар», «Русский размер» и мн. др. Одним из популярных и полюбившимся русскими мест является ночной клуб «Blues Bar», он же «Болозы Джейба». В основном его посещают русские студенты, танцовщицы, проститутки, бизнесмены. В рекламных целях клуб использует русскую тему, что привлекает в него большое количество самой интернациональной публики (Курто, 2011, стр. 131-145).

Своеобразную сферу в жизни русской диаспоры составляли кабаре «Вигвам», «Кривой Купидон», «Ко всем чертям», «Бродячие собаки», «Chat noir», «Летучие мыши», «Black cat» и мн. др., возникавшие в среде актеров, художников, поэтов и музыкантов. Постепенно кабаре становились доступными и для обывателей. Для многих китайцев русские кабаре стали излюбленным местом, особенно если в них имелась китайская этническая специфика и присутствовали русские женщины. В отдельном городе Китая одновременно действовало несколько кабаре, где можно было встретить множество китайцев. «Кто с женой избрал банальность, в Ша-нуар не приходи. / В Ша-нуаре не обычно - и особый четкий стиль / Временами неприлично - но приличие - костыль!» (Песенка Ша-нуара) (Черкашина, 2001, стр. 57-62).

Процесс гибридизации приводит в конечном итоге к появлению целого ряда новых культурных свойств, форм, явлений в истории России и Китая. В ответ на приток русских иммигрантов литературные, театральные и музыкальные произведения стали регулярно появляться в XIX - XX вв. 
В 1907 г. в китайской истории впервые обратились к постановкам русской драматургии. Обществом «Чунь лю» была поставлена пьеса по мотивам романа Л.Н. Толстого «Воскресенье». Спустя несколько лет к этому роману обратилась женская труппа «Куй дэшэ» (Сияющая добродетель) и создала спектакль «Отказ от свадьбы». С 1919 по 1924 гг. на сцене китайского театра ставили «Власть тьмы» Л.Н. Толс того, «Грозу» А.Н. Островского. В 1921 г. в Тяньцзине «Новая нанькинская театральная труппа» осуществила постановку по мотивам произведения Н.В. Гоголя «Ревизор» в переводе Хэ Цинмина. Постановка получила живой отклик у китайской публики, стала транслироваться в Китае в разных вариантах перевода. Герои в пьесе имели китайские имена и были одеты в китайские костюмы чиновников. В 1938 г. систему К.С. Станиславского на уроках актерского мастерства стали применять Хуан Цзолинь и Дань Ни.

В начале XXI в. между Россией и Китаем существует сильное притяжение в области театрального искусства, что напрямую свидетельствует о функционировании процесса культурной гибридизации. Китайские режиссеры стремятся адаптировать пьесы А.П. Чехова в современной китайской драме, сохраняют специфику системы принципов Чехова. В истории китайского театра разговорной драмы хуацзюй первое обращение к постановкам драматургии Чехова происходит в 1930-е гг. ставят спектакли «Иванов», «Дядя Ваня», «Три Сестры», «Вишневый сад». Активная межкультурная коммуникация русских и китайцев позволила создать на сцене новое культурное явление, как, например, совместная творческая работа режиссеров МХАТ Владимира Петрова и Ван Пэна в 2013 г. - спектакль «Шесть персонажей в поисках автора» (Шулунова, 2014, стр. 431-434).

Образы восприятия гибридного пространства транслировались в общероссийскую культуру носителями этого опыта культурной гибридности - русскими поэтами иммигрантами. Лирические зарисовки китайского быта, отлично отражают постепенное вливание русских в этот новый мир:

Сижу с китайцами в харчевнях,

Ведя бесед несложных ряд, И странной радостью напоен

Мой каждый в быт Китая взгляд!

(М. Спургот «Сижу с китайцами в харчевнях...», 1931)

Эти небольшие четыре строчки стихотворения показывают межкультурную коммуникацию китайцев и русских, где культура Китая в сознании русского иммигранта становиться также близка и дорога, как и 
самим китайцам (Забияко, Забияко, Левошко, Хисамутдинов, 2015, стр. 189-190). Также мы находим в данных сюжетах гибридную идентичность: «Художник - я, и, несомненно, русский, / Но не лишенный иностранных черт» (Н. Щёголев «Русский художник»).

Образы особенных гибридных - харбинских времен года коррелируют у А. Паркау со встречей с Другим/Чужим, а также с воспоминаниями о России:

Харбинская... весна... Гудят автомобили, Кругом густая мгла, пирушка злобной тьмы, Китайцьь все в очках от ветра и от пьли, Японцы с масками от гриппа и чумы.

Очки чудовищны, и лица странно жутки, В смятенном городе зловещий маскарад.

Ни снега талого, ни робкой незабудки, Ни звонких ручейков, ни вешних серенад.

(А. Паркау «Харбинская весна»)

Отношение к Другому/Чужому пространству как нельзя лучше отразилось в признании Маньчжурии в любви, лирическим героем Е. Яшнова, который обращается к аргументации через доступные человеку чувства - осязание, зрение, слух и др.: «Пыль сладковатую дорог, // Чужой пейзаж, чужой порог, // Восточной девушки ланиты // И речи кружево чужой // Люблю бродяжною душой» («В Маньчжурии») (Эфендиева, 2011, стр. 72-78).

В стихотворении Н. Щёголева «В раздумье» накладывается образ России на свое маньчжурское пространство:

...Но так безумно я мечтаю,

С такою верностью люблю,

Что даже и в часы лихие,

В болезни, гнете и тоске,

Все мнится мне, что я в России,

А не в маньчжурском городке...

(Н. Щёголев «В раздумье»)

Изначально Китай помог русским иммигрантам из России выжить и подарил своеобразный облик восточной ветви русского зарубежья. 
Сначала он помог удалиться от тягот реальной жизни и погрузиться в тайны чужой истории, чужой культуры, чужой земли. Затем стал источником новых тем и сюжетов (стр. 158-177). Ключевыми строками являются: «Все мниться мне, что я в России, / А не в маньчжурском городке», в которых новый город, новое пространство воспринимается поэтом как пространство «Между». Данные строки отражают сложившееся гибридное пространство. В этой поэзии писатели часто принимали различную позицию живущего в чужом месте и проектирующего реальность Другого (Barker, Gheith, 2004, стр. 163). Все это есть результат встречи с Другим/Чужим, чужой территорией, которое испытали многие русские, оказавшиеся свидетелями строительства нового большого чудесного гибридного пространства в городах Китая. Многие писатели, художники, композиторы, очутившись в изгнании, в своих мемуарах признавали, что им «не хватает российского пространства, шире воздуха» и не ловко вживаться в новую среду, таинственную и пугающую (Говердовская, 2000, стр. 123).

Встреча с Чужим в условиях культурной гибридности очень ярко проявляется в популярном на Дальнем Востоке сборнике рассказов «Звезды Маньчжурии», написанным писателем-эмигрантом А.П. Хейдоком. «Звезды Маньчжурии» - это исключительно гибридный продукт, представляет собой некий сплав духовных культур китайцев, русских, монголов. В сборнике также есть выходы на египетскую мифологию, представления о жизни современного западного человека. Через диалог двух человек автор показал столкновение двух культур, двух способов мышления и видения мира (Мяо, 2014, стр. 133-142). Конструирование образа Другого/Чужого происходит по линии метафорического переноса его в разряд монстров, животных и т.д. Происходит демонизация или монстроизация Другого/Чужого (Якушенков, Якушенкова, 2012, стр. 233-240). Неудивительно, что в гибридных рассказах А.П. Хейдока есть место существованию таинственного дьявола, чертей, демонов, нечистой силы, сил темного царства, а также есть место удивительным мыслям, сверхъестественному, божественному, столкновения с чудом, мистической природой (Мяо, 2014, стр. 133-142). Подобное гибридное произведение сформировалось в результате тесного сочетания в рассказах автора китайской культуры, народных обычаев, мифов, верований (буддизма, даосизма и др.), пространства Маньчжурии и культуры русского человека, его мировосприятия. Именно это сочетание диаметрально противоположного сделало сборник «Звезды Маньчжурии» таким интересным и популярным на Дальнем Востоке и упрочнило положение А.П. Хейдока в русской литературе эмиграции. 
Другой/Чужой в истории Китае - это либо «варвар», либо «заморский дьявол». Но важно понимать, что отношение к Другому/Чужому претерпевало изменения в истории Китая. Этноцентрическое отношение к Другому/Чужому, сменялось на сопоставительное. Китай выводили из кризиса посредством перезапуска ментальной модели организации сознания (Крюков, Малявин, Софронов, Чебоксаров, 1993). В период формирования русской диаспоры в Китае, русские, конечно, воспринимались как Других/Чужих, но не характеризовались как вторгающееся, раздражающее, атакующее, заполняющее, вытесняющее, причиняющая сила. С первых годов своего поселения на новой родине русская этническая группа не почувствовала на себе явного проявление китайского этноцентризма, шовинизма, ксенофобии, национализма и дискриминации как результата встречи с Чужим: восприятие культуры русского этноса не происходило в рамках «Другой/Чужой - Враг»; формирование русской диаспоры не затруднило межкультурную коммуникацию русских и китайцев, а наоборот сблизило их; русские и китайцы не почувствовали на себе «культурный шок», пытаясь воспринять культуру, отличающуюся от их собственной; активно формировались межнациональные браки; не сложилось явного сегрегированного закрытого общества; этнические русские работали в качестве ученых, инженеров, врачей, учителей, солдат и офицеров, фермеров, торговцев, водителей и пр. - обладая высокой квалификацией русским иммигрантам удалось со временем сформировать элиту в Китае (Shear, 2013, стр. 292-298).

Однако, в истории Китая существовали периоды обострения негативного отношения к русским. Победа коммунистов в Синьцзяне положила начало конца русской диаспоры. Это событие произошло 10 ноября 1949 г., когда большие группы беженцев, в основном белых русских, отправлялись на границу с Индией. А в феврале 1950 г. Советский Союз и новая Китайская Народная Республика подписали договор о дружбе и союзе - «Русский и китаец - братья навек». В результате этого договора тысячи советских беженцев вернулись в Синьцзян. Но это была лишь временная пружина для русской диаспоры. Начиная с 1956 г. отношения между этими двумя коммунистическими сверхдержавами ухудшились. В 1961 г. советские консульства в Урумчи, Кульдже и Кашгаре были закрыты. Этнические русские столкнулись с дискриминацией. Эта ситуация началась в 1950-е гг. и продолжилась ухудшаться до 1962 г.

В 1966 г. началась Культурная революция в Китае, которая вызвала «культурный шок» во многих городах Китая, в том числе и в Синьцзяне. Сформировались анти-иностранные чувства, антирусские настроения, а в дальнейшем и русофобия, которые привели к бегству практически всех 
русских из Синьцзяна (Shear, 2013, стр. 292-298). Поколения метисов от русско-китайских браков подвергались массовой дискриминации и репрессиям по обвинению в шпионаже в пользу СССР. Русский язык оказался под строгим запретом, быть русским и говорить по-русски во время Культурной революции стало опасно. Многие русские православные храмы были уничтожены (Тарасов, 2016, стр. 102-121). Нынешние «элосыцзу» - русские предпочитают не вспоминать эти тяжелые испытания, которые выпали на их долю в период Культурной революции. Для нынешнего русского Китай - это страна, благодаря которой он и его предки смогли выжить (Гутин, 2011, стр. 50-56).

Однако обратим внимание на то, что пресловутые образы «казаков» - злых агрессоров или коварной Российской империи, воспользовавшейся трудностями Китая для заключения неравноправных договоров, до сих пор властвуют над умами и эмоциями многих китайцев. Оценка российской политики XIX - начала XX вв., как политики колониальных захватов известна каждому китайскому школьнику.

Этнофолизмом в отношении русских служило слово «ламоза». Словами «ламоза лайла» - русский пришел - китаянки пугали своих капризничавших детей. С именем «ламоза» сочеталось представление о людях, наделенных колдовской силой, о людях страшных, волосатых, пугающих, о которых китайцы говорили недоброжелательно (Забияко, Кобызов, Понкратова, 2009, стр. 155-165).

Эти периоды и отдельные моменты в история Китая отчетливо показывают изменение отношения к Другому/Чужому. В свою очередь, процесс культурной гибридизации в данные периоды в истории русской диаспоры приобретает особые черты. При этом заметим, что процесс культурной гибридизации после Культурной революции в отдельных местах Китая прекращается, а где-то уничтожается. Изменение отношения к Другому/Чужому неразрывно влияет на процесс культурной гибридизации.

Сегодня подавляющее большинство потомков этнических русских живут в Синьцзяне. По данным переписи населения за 2002 г., примерно 9000 русских остаются в Синьцзяне, образуя небольшой процент от общего числа населения (Shear, 2013, стр. 292-298). Начиная со второй половины 1990-х гг. в Синьцзяне снова появились русские (Монгуш, 2016, стр. 2-8), которые формируют продолжение истории русских в этом регионе, создавая гибридную культуру.

Заключение. Таким образом, из нашего исследования видно, что процесс культурной гибридизации - это процесс смешивания, сочетания различных культур, зачастую диаметрально противоположных, в результате которого происходит образование гибридной культуры - новой 
культуры. Процесс культурной гибридности в различных местах и периодах времени истории разнообразен и имеет свою уникальную специфику по целому ряду причин: особенности территории; наличия точек соприкосновения культур у двух или более народов; характера межкультурной коммуникации между этносами; особенности исторического развития общества и мн. др.

Описанный выше процесс наталкивает на мысль, что культурная гибридность в разных местах представляется в различных вариантах. По многим показателям процесс культурной гибридности в Китае будет незначительным образом отличаться от подобных явлений в России, США, Европе или Африке. Сравнение различных видов или типов процесса культурной гибридизации позволяет нам выявить множество различий, но их сходство позволит объединить их всех одним универсальным концептом - культурная гибридность. А это означает, что культурная гибридность - культурно-историческое явление. Вместе с тем, данный подход применим к большинству смешанных пространств в истории человечества.

\section{Список литературы}

Barker, A.M. \& Gheith, J.M. (2004). A History of Women's Writing in Russia. Cambridge: Cambridge University Press.

Burke, P. (2012). A Case of Cultural Hybridity: the European Renaissance. Germany: Max Planck Institute for Social Anthropology.

Burke, P. (2009). Cultural Hybridity. Cambridge: Polity Press. Press.

Dawkins, R. (1976). The Selfish Gene. New York: Oxford University

Shear, M. (2013). Strangers in a strange land: the Russian community in Xinjiang, and its interactions with the local peoples. Каспийский регион: политика, экономика, культура, 3 (36), стр. 292-298.

Sheldon, H. Lu. (2000). Soap Opera in China: The Transnational Politics of Visuality, Sexuality, and Masculinity. Cinema Journal, №40 (1), стр. 25-47.

Young, Robert J. C. (1995). Colonial Desire: Hybridity in Theory, Culture and Race. London, New York: Routledge.

Аурилене, Е.Е. (2013). Судьбы русской эмигрантской культуры в Китае (1920-1940-е гг.): региональный фактор. Проблемь Дальнего Востока, 3, стр. 128-136.

Го, Мен. (2012). Миграция населения из России в Китай: исторический опыт натурализации и сохранения самобытности (конец XVII - XX века). Локус: люди, общество, культуры, смыслы, 2, стр. 71-77. 
Говердовская, Л.Ф. (2000). Общественно-политическая и культурная деятельность русской эмиграции в Китае в 1917-1931 г2. Москва: МАДИ.

Гончаренко, О.Г. (2009). Русский Харбин. Москва: Вече.

Грибин, С. (2008). «Харбинское пиво»- русские корни? Любителям пива и путешествий. Школа жизни. py. Retrieved from https://shkolazhizni.ru/meal/articles/13240

Гутин, Ю.И.(2011). Русские в КНР. Азия и Африка сегодня, 10, стр. 50-56.

Забияко, А.А. \& Забияко, А.П. \& др. (2015). Русский Харбин: опыт жизнестроительства в условиях дальневосточного фронтира . Благовещенск: Амурский государственный университет.

Забияко, А.А. \& Забияко, А.П. \& др. (2016). Фольклор рускоязычной диаспоры Трёхречья как основа сохранения этничности. Известия Иркутского Госудасртвенного университета, 17, стр. 109-125.

Забияко, А.П. \& Кобызов Р.А. \& др. (2009). Русские и китайцьы: эмиграционные проиессы на Дальнем Востоке. Благовещенск: Амурский государственный университет.

Корчагина, О.А. (2016). Города-сады Дальнего Востока в начале XX века: Дальний, Порт-Артур, Харбин. Актуальные проблемы теории и истории искусства, 6, стр. 668-675.

Крадин, Н.П. (2001). Харбин - русская Атлантида. Хабаровск: Издатель Хворов А.Ю.

Крюков, М.В. \& Малявин, В.В. \& др. (1993). Этническая история китайцев XIX - начале XX века. Москва: Восточная литература.

Курто, О.И. (2011). Понятие «русские харбинцы» и его современное значение. Этнографическое обозрение, 1, стр. 131-145.

Лю, Лифэнь. (2016). Сопоставление семантических полей русских и китайских кулинарных глаголов «печь 烤》 и «парить蒸》. Филологические науки. Воспросы теории и практики, 12-1 (66), стр. 116-121.

Монгуш, М.В. (2016). Русское культурное наследие в Синьцзяне. Журнал Института наследия, 2 (5), стр. 1-8.

Мяо, Хуэй. (2014). Особенность отражения китайской культуры в рассказах А. Хейдока. Гуманитарный вектор, 2 (38), стр. 133-142.

Мяо, Хуэй. (2015). Русская эмиграция в Харбине: взаимодействие двух культур. Гуманитарныий вектор, 2 (42), стр. 128-135.

Оглезнева, Е.А. (2010). Российско-китайское взаимодействие на дальневосточных территориях России: историко-лингвистический очерк. Слово: Фольклорно-диалектический альманах, 8, стр. 6-25.

Романова, А.П. \& Хлыщева, Е.В. \& др. (2013). Чужой и культурная безопасность. Москва: РОССПЕН. 
Ставров, И.В. (2016). Элосыцзу- осколок Русского мира в Китае (о положении русского этнического меньшинства в КНР). Россия и ATP, 4 (94), стр. 116-133.

Старосельская, Н.Д. (2006). Повседневная жизнь «русского» Китая. Москва: Молодая Гвардия.

Тарасов, А.П. (2016). Русская национальная волость Эньхэ в Барге: поиск русскими своей национальной идентичности в Приграничном Китае. Проблемь Дальнего Востока, 1, стр. 102-121.

Тен, Н.В. (2010). Представления севременных китайцев о русском народе и его основных чертах. Этнографическое обозрение, 4, стр. 189200.

Хаиндрова, Л.Ю. (2003). Сердие поэта. Калуга: Полиграф-Информ.

Хисамутдинов, А.А. (2013). Русские женщины в Китае (1922-1940-е гг.). Проблемы Дальнего Востока, 2013 г., 3. стр. 124-127.

Черкашина, С.А. (2001). Традиции серебряного века в культуре русской эмиграции в Китае. Поблемь подготовки кадров для сферы искусства и культуры. Материал научной конфиренциии, стр. 57-62.

Шулунова, Е.К. (2014). Драматический театр Китая хуацзюй и русская театральная культура. Благовещенский государственный педагогический университет, стр. 431-434.

Эфендиева, Г.В. (2011). Проблема этнической идентификации поэтов-эмигрантов русского Харбина. Русский язык за рубежом, 1 (224), стр. 72-78.

Якушенков, С.Н. (2016). Культурные процессы в гетеротопных пространствах (на примере нижнего поволжья). Кочевые народы юга России: Исторический опьыт и современность, стр. 419-422.

Якушенков, С.Н. (2017). На границе тучи ходят хмуро, край суровый тишиной объят. Часть 2. Journal of Frontier Studies, 1 (5), стр. 8-36.

Якушенков, С.Н. \& Романова, А.П. \& др. (2011). «Гляжусь в тебя, как в зеркало, до головокружения», или протообразы тела Чужого в российском дискурсе. Каспийский регион: политика, экономика, культура, 1, стр. 189-195.

Якушенков, С.Н. \& Якушенкова, О.С. (2012). Тело варвара: Конструирование образа Чужого на китайском фронтире. Каспийский регион: политика, экономика, культура, 4 (33), стр. 233-240.

Якушенков, С.Н. \& Сун, Цзе. (2015). Культурная безопасность и факторы развития национальной алиментарной культуры. Каспийский регион: политика, экономика, культура, 4 (45), стр. 247-253.

Якушенков, С.Н. \& Якушенкова, О.С. (2016). «Власть земли»: формирование новой инаковости в условиях фронтира. Journal of Frontier Studies, 1, стр. 5-21. 
Якушенкова, О.С. (2014). Образы сексуальности Чужого как фактор, маркирующий фронтирную гетеротопию. Каспийский регион: политика, экономика, культура, 2 (39), стр. 346-352.

\title{
RUSSIAN DIASPORA IN CHINA: VARIANT OF CULTURAL HYBRIDITY
}

\author{
Meshcheryakov A.Yu., Antropov O.K.
}

Antropov Oleg Konstantinovich, Astrakhan State University, 414056, Astrakhan, Russia, Tatischeva Str., 20a. E-mail: olegantropov1 @ gmail.com

Meshcheryakov Alexander Yurievich, Astrakhan State University, 414056, Astrakhan, Russia, Tatischeva Str., 20a. E-mail: daomesheryakov@ gmail.com

The authors analyze the process of cultural hybridization in the Russian Diaspora of China. The process of cultural hybridization is a mix of cultures or an intersection, where the formation of new terms, properties, laws and other existential rules. This process of cultural hybridization in the history is seen by the authors in a variety of forms. Cultural hybridity occurs in such places where for a long time are racial, linguistic, religious and other cultural contacts. It is in the dialogue of cultures the cultural hybridity is born. Cultural dialogue with the Other/Stranger in the Chinese territory have contributed to the emergence of cultural hybridity. The Russian Diaspora in China was an ideal place to study cultural hybridity, due to its intersection of the Russian and Chinese cultures.

A special form of interethnic interaction of Russian and Chinese became the mixed Russian-Chinese marriage being "in-between" the two cultures. The result is an interracial, mixed, international marriages, there is a generation of mixed -race children - the carriers of a new culture. The cultural identity of immigrants on foreign soil in any case changed and become another identity - a hybrid identity. The process of cultural hybridization in the end led to the emergence of a number of new cultural properties, forms, and phenomena in the history of Russia and China. The article presents images of perception of hybrid space, broadcast in Russian culture bearers of this experience of cultural hybridity: Russian poets, artists, musicians, actors, etc.. . According to the authors, cultural hybridity in different places and periods of history, diverse and has unique specificity for a number of reasons

Key words: hybrid, cultural hybridity, cultural encounters, hybrid identity, hybrid space, Other/Alien, Russian diaspora, Russian immigration, Russia, China.

\section{References}

Barker, A.M. \& Gheith, J.M. (2004). A History of Women's Writing in Russia. Cambridge: Cambridge University Press.

Burke, P. (2012). A Case of Cultural Hybridity: the European Renaissance. Germany: Max Planck Institute for Social Anthropology.

Burke, P. (2009). Cultural Hybridity. Cambridge: Polity Press. 
Dawkins, R. (1976). The Selfish Gene. New York: Oxford University Press.

Shear, M. (2013). Strangers in a strange land: the Russian community in Xinjiang, and its interactions with the local peoples. The Caspian region: politics, economy, culture, 3 (36), стр. 292-298.

Sheldon, H. Lu. (2000). Soap Opera in China: The Transnational Politic s of Visuality, Sexuality, and Masculinity. Cinema Journal, №40 (1), стр. 25-47.

Young, Robert J. C. (1995). Colonial Desire: Hybridity in Theory, Culture and Race. London, New York: Routledge.

Aurilene, E.E. (2013). The fate of Russian emigre culture in China (1920-1940): a regional factor. Problems of the Far East, 3, pp. 128-136.

Go, Men. (2012). Migration of the population from Russia to China: the historical experience of naturalization and preservation of identity (the end of the XVII - XX century). Locus: people, society, cultures, meanings, 2, pp. 7177.

Goverdovskaya, LF (2000). The socio-political and cultural activities of Russian emigration in China in 1917-1931. Moscow: MADI.

Goncharenko, O.G. (2009). Russian Harbin. Moscow: Veche.

Gribin, S. (2008). «Harbin beer» - Russian roots? Beer and travel lovers. School of Life. ru. Retrieved from https://shkolazhizni.ru/meal/articles/13240 50-56.

Gutin, Yu.I. (2011). Russian in the PRC. Asia and Africa today, 10, pp.

Zabiyako, A.A. \& Zabiyako, A.P. \& Others (2015). Russian Harbin: experience of life-building in the conditions of the Far Eastern frontier. Blagoveshchensk: Amur State University.

Zabiyako, A.A. \& Zabiyako, A.P. \& Quot; (2016). Folklore of the Russian-speaking diaspora of the Three Rivers as a basis for the preservation of ethnicity. Proceedings of the Irkutsk State University, 17, pp. 109-125.

Zabiyako, A.P. \& Kobyzov RA \& Etc. (2009). Russian and Chinese: emigration processes in the Far East. Blagoveshchensk: Amur State University.

Korchagin, O.A (2016). Cities-gardens of the Far East in the early XX century: Far, Port Arthur, Harbin. Actual problems of theory and art history, 6, pp. 668-675.

Kradin, N.P. (2001). Harbin - Russian Atlantis. Khabarovsk: Publisher Khvorov A.Yu.

Kryukov, M.V. \& Malyavin, V.V. Et al. (1993). Ethnic history of the Chinese XIX - early XX century. Moscow: Eastern Literature.

Courto, O.I. (2011). The notion of «Russian Harbinians» and its modern meaning. Ethnographic Review, 1, pp. 131-145.

Lyu, Lifen. (2016). Comparing the semantic fields of the Russian and Chinese culinary verbs «to bake» and «to steam». Philology. Peculiarities of theory and practice, 12-1 (66), pp. 116-121. 
Mongush, M.V. (2016). The Russian cultural heritage in Xinjiang. Journal of the Institute of Heritage, 2 (5), pp. 1-8.

Miao, Hui. (2014). Peculiarities of the Chinese Culture Reflection in A. Kheydok's Stories. Humanitarian vector, 2 (38), pp. 133-142.

Miao, Hui. (2015). Russian immigration in Harbin: interaction of two cultures. Humanitarian vector, 2 (42), pp. 128-135.

Oglezneva, E.A. (2010). Russian-Chinese interaction in the Far Eastern territories of Russia: historical and linguistic essay. Word: Folklore-dialectical almanac, 8, pp. 6-25.

Romanova, A.P. \& Khlyshcheva, E.V. \& Others (2013). Alien and cultural security. Moscow: ROSSPEN.

Stavrov, I.V. (2016). Elositszu - a fragment of the Russian world in China (on the situation of the Russian ethnic minority in China). Russia and the Asia-Pacific Region, 4 (94), pp. 116-133.

Staroselskaya, N.D. (2006). The daily life of «Russian» China. Moscow: The Young Guard.

Tarasov, A.P. (2016). Russian county Enhe in Barga: quest for national identity in near-border China. Problems of the Far East, 1, pp. 102-121.

Ten, N.V. (2010). Representations of the Chinese people of the time of the n people and its main features. Ethnographic Review, 4, pp. 189-200. Inform.

Khaindrova, L.Yu. (2003). The heart of the poet. Kaluga: Polygraph-

Hisamutdinov, A.A. (2013). Russian women in China (1922-1940). Problems of the Far East, 2013, 3. pp. 124-127.

Cherkashin, S.A. (2001). Traditions of the Silver Age in the culture of Russian emigration in China. Problems of training for the arts and culture. Material of Scientific Confirmation, pp. 57-62.

Shulunova, E.K. (2014). The drama theatre China Huaju and the Russians theatrical culture. Blagoveshchensk State Pedagogical University, pp. 431-434.

Efendieva, G.V. (2011). The problem of ethnic identification of poetsemigrants of Russian Harbin. Russian language abroad, 1 (224), pp. 72-78.

Yakushenkov, S.N. (2016). Cultural processes in heterotopic spaces (the example of the lower Volga region). Nomadic peoples of the south of Russia: Historical experience and the present, pp. 419-422.

Yakushenkov, S.N. (2017). Gloomy clouds cover the border - the stern land is enveloped in silence. Part 2. Journal of Frontier Studies, 1 (5), pp. 8-36.

Yakushenkov, S.N. \& Romanova, A.P. \& Others (2011). «I look in you like a mirror, before dizziness», or prototypes of the body of the Alien in Russian discourse. The Caspian region: politics, economics, culture, 1, pp. 189195. 
Yakushenkov, S.N. \& Yakushenkova, O.S. (2012). The body of the barbarian: Designing the image of the Alien on the Chinese frontier. The Caspian region: politics, economy, culture, 4 (33), p. 233-240.

Yakushenkov, S.N. \& Song, Jie. (2015). Cultural security and factors of development of national alimentary culture. The Caspian region: politics, economics, culture, 4 (45), pp. 247-253.

Yakushenkov, S.N. \& Yakushenkova, O.S. (2016). «The power of the earth»: the formation of a new differentness in the conditions of the frontier. Journal of Frontier Studies, 1, pp. 5-21.

Yakushenkova, O.S. (2014). The images of the sexuality of the Alien as a factor of marks of frontier heterotopy. The Caspian region: politics, economy, culture, 2 (39), p. 346-352. 